\title{
Filtered tailings versus thickened slurry: four case studies
}

\author{
T.G. Fitton ATC Williams Pty Ltd, Australia
}

A. Roshdieh ATC Williams Pty Ltd, Australia

\begin{abstract}
Shortage of water (or a high cost of water) drives miners to look towards more costly water extraction technology for their tailings. Filtration technology offers greater water recovery than the more commonly used thickening technology, but this comes at a greater cost, both in terms of capital outlay as well as its operation. The transport of the filtered tailings exacerbates this problem, particularly where long distances come into play. The storage of the filtered tailings can sometimes be achieved at less cost than that of thickened tailings slurry, depending on the topography of the surrounding area. The economic feasibility of filtration technology over slurry thickening technology ultimately comes down to the cost of the make-up water that is required.
\end{abstract}

This paper presents four different copper mining operations in which these two technologies have been considered for the treatment of tailings. In each case study the tailings dewatering, transport, storage and closure has been designed and costed, both in terms of capital and operating expenses. The overall findings of each study are presented and discussed. Finally, the break-even point for filtration at each mine has been estimated, in terms of the water cost.

\section{Introduction}

A number of dewatering technologies are currently in use in the mining industry for the recovery of water from the tailings stream. The most common of these is the thickener. Thickener technology comes in a variety of forms, ranging from 'conventional' thickeners at the least effective end of the scale, through to 'high-rate', 'high density' or 'high compression' and finally 'paste' thickeners at the most effective end of the scale. Generally the height of the thickener increases as one goes from conventional thickeners to a paste thickener. So does the cost, as does the density of the slurry that emerges from the bottom of the thickener as 'underflow'.

Other technologies are also used for the extraction of water, such as cyclones, screens and filtration. Filtration generally results in the greatest water recovery, but the product of the process is no longer a fluid; instead it is a moist soil that is referred to as 'filter cake'.

An indication of the slurry concentrations that can typically be obtained with the utilisation of various dewatering technologies with copper tailings is presented in Table 1.

Table 1 Typical slurry concentrations for copper tailings

\begin{tabular}{lc}
\hline State of copper tailings & Typical solids concentration \\
\hline Unthickened tailings slurry ex concentrator & $20-25 \% \mathrm{w} / \mathrm{w}$ \\
High rate thickener underflow & $50-58 \% \mathrm{w} / \mathrm{w}$ \\
High density / high compression thickener underflow & $57-68 \% \mathrm{w} / \mathrm{w}$ \\
Paste thickener underflow & $60-71 \% \mathrm{w} / \mathrm{w}$ \\
Cake from vacuum filter & $77-82 \% \mathrm{w} / \mathrm{w}$ \\
\hline
\end{tabular}




\begin{tabular}{ll}
\hline Cake from filter press & $80-85 \% \mathrm{w} / \mathrm{w}$ \\
\hline
\end{tabular}

\section{$2 \quad$ Tailings transport}

Tailings slurry can be transported by gravity flow if the tailings storage facility (TSF) is sufficiently lower than the concentrator. Such gravity flow can be achieved in long distance open channel flumes (as is done in a number of copper mines in Chile and Iran), or in pipelines without pumps. In less favourable topography the slurry must be transported with pumps and pipelines, although slurry with a large enough yield stress value will require positive displacement pumps and a high pressure pipeline. Cake requires conveyor belts and/or earthmoving equipment to transport it.

\section{$3 \quad$ Tailings storage}

The tailings storage site is also greatly influenced by the amount of dewatering that is occurring upstream. Low density tailings slurry that is hydraulically discharged typically forms a deposit with minimal slope, so it must be contained in an impoundment with one or more large embankments to retain it. High density tailings slurry forms a deposit with beach slopes typically in the order of $1-3 \%$. In flat terrain this beach slope can be exploited by allowing it to form a conical mound with smaller perimeter embankments to contain it. In mountainous terrain such slurry can be stored as a sloping deposit down a valley, typically with an embankment required at the lower end of the valley. Filter cake is stored in a dry stack. This requires a greater amount of handling in order to spread it across the storage site, and essentially becomes another exercise in earthmoving. It is noted that stacking conveyor systems are available for carrying out the major part of the distribution of tailings sand or tailings cake.

\section{$4 \quad$ Water return}

In all of the case studies presented here, the water recovered from the dewatering process was pumped back to the concentrator for recycling. Such water return infrastructure has been included in the cost for each design. However, due to the arid nature of the sites studied, no water return infrastructure from the TSF was included at this level of study, except where conventional impoundment storages were considered.

\section{$5 \quad$ The four case studies}

In this paper four copper mines are considered. Each of these four mines was recently the subject of an options study, in which various options were considered for the tailings storage type and location. In all cases an initial screening of potential TSF sites had previously been carried out, so a storage site had already been decided from this process.

The focus of this paper is the interaction between the tailings slurry dewatering infrastructure and the storage method and transport infrastructure for each mine. In each of the four case studies a number of configurations and locations for slurry dewatering infrastructure were considered. The tailings storage and slurry transport infrastructure was then designed to suit. The main driver for all of the studies was the economic outcome in terms of Net Present Cost, but each study featured other drivers too, with water conservation being the one common theme. In each case study the tailings processing, transport, storage and closure has been designed and costed, both in terms of capital and operating expenses.

Note that mine names and operators have not been identified in this paper. Instead each mine shall be referred to as Mine 1, Mine 2 etc.

A summary of the key aspects of each of the four mines is presented in Table 2. 
Table 2 Key parameters for each case study

\begin{tabular}{lll}
\hline & Production & Route to TSF \\
\hline Mine 1 & 7 Mtpa for 20 years & $\begin{array}{l}33.9 \mathrm{~km}, 870 \mathrm{~m} \text { fall (slurry) } \\
12 \mathrm{~km}, 370 \mathrm{~m} \text { fall (dry stack) }\end{array}$ \\
Mine 2 & 25 Mtpa for 26 years & $10 \mathrm{~km}, 10 \mathrm{~m}$ rise \\
Mine 3 & 32 Mtpa for 30 years & $24 \mathrm{~km}, 1,300 \mathrm{~m}$ fall (slurry) \\
& & $6 \mathrm{~km}, 50 \mathrm{~m}$ fall (dry stack) \\
Mine 4 & \multirow{2}{*}{ 47 Mtpa for 29 years } & $25 \mathrm{~km}, 1,600 \mathrm{~m}$ fall (slurry) \\
& & $6 \mathrm{~km}, 50 \mathrm{~m}$ fall (dry stack) \\
\hline
\end{tabular}

\subsection{Mine 1}

This copper mine is located in a mountainous area with an extremely dry climate. The tailings production rate will be 7 million tonnes per year (Mtpa) for a mine life of 20 years. Due to water supply limitations, the mine owner has stipulated that paste thickeners or filter presses must be used. The client has also asked that slurry pumps be avoided (or their use minimised) as much as possible. At this site, the cost of water has been set at $\$ 3.63$ USD per $\mathrm{m}^{3}$.

A central thickened discharge type tailings storage facility was designed for the paste thickener underflow. The TSF was situated in a wide alluvial plain at the foot of the mountains, some $34 \mathrm{~km}$ away from the mine, in a location some $870 \mathrm{~m}$ lower. A number of low earthen embankments are required to retain the tailings. This TSF is presented in Figure 1. It is noted that a number of down valley discharge type TSFs were designed for this mine in previous studies, but despite being much closer to the mine, all were found to be far more costly due to the large embankments that were required to retain the tailings.

For the filter option, a separate dry stack TSF was designed for a site $12 \mathrm{~km}$ to the south of the proposed concentrator, up against a hill. This site is about $370 \mathrm{~m}$ lower than the concentrator. This TSF is presented in Figure 2. 


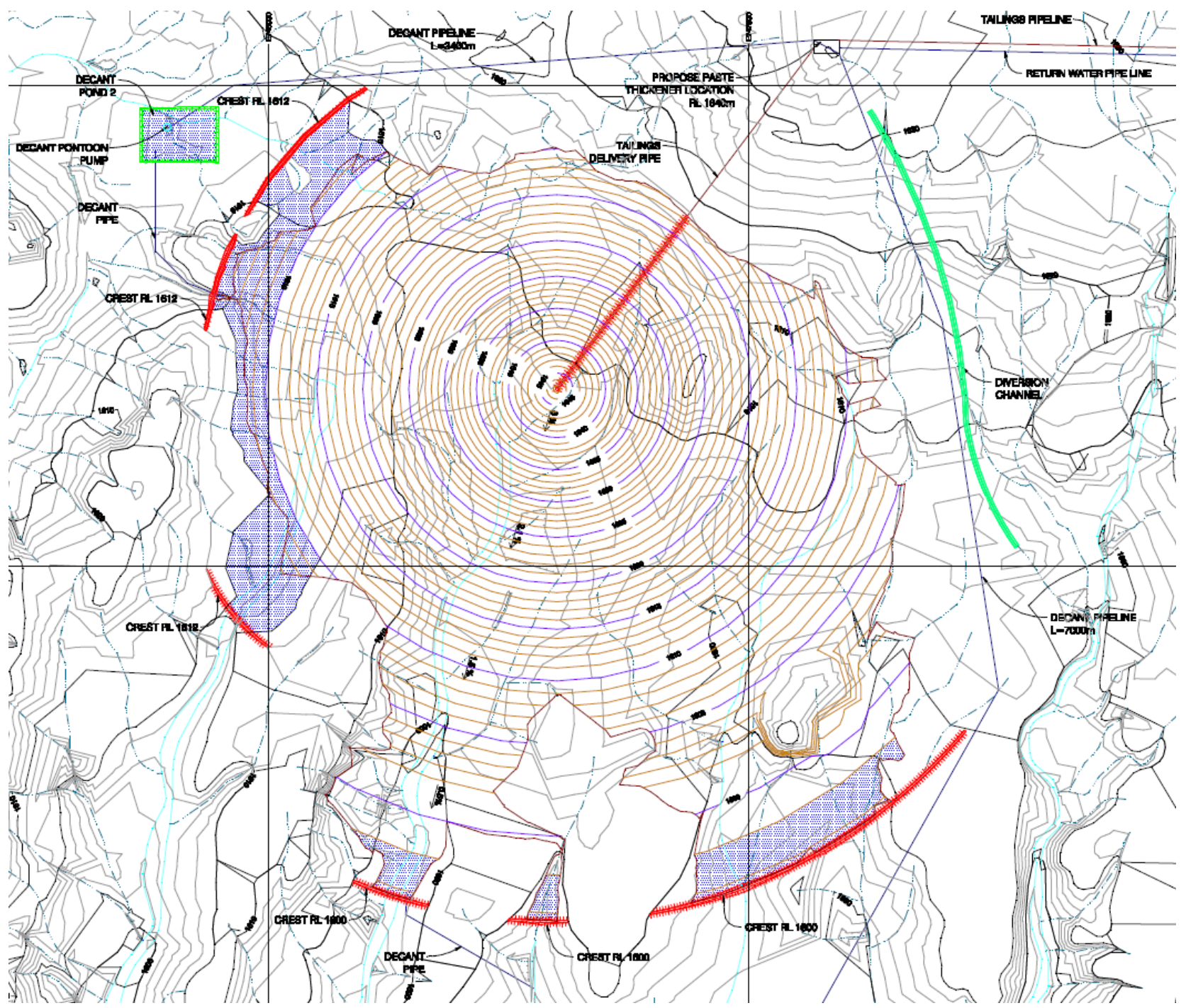

Figure 1 The central thickened discharge TSF that was modelled for Mine 1

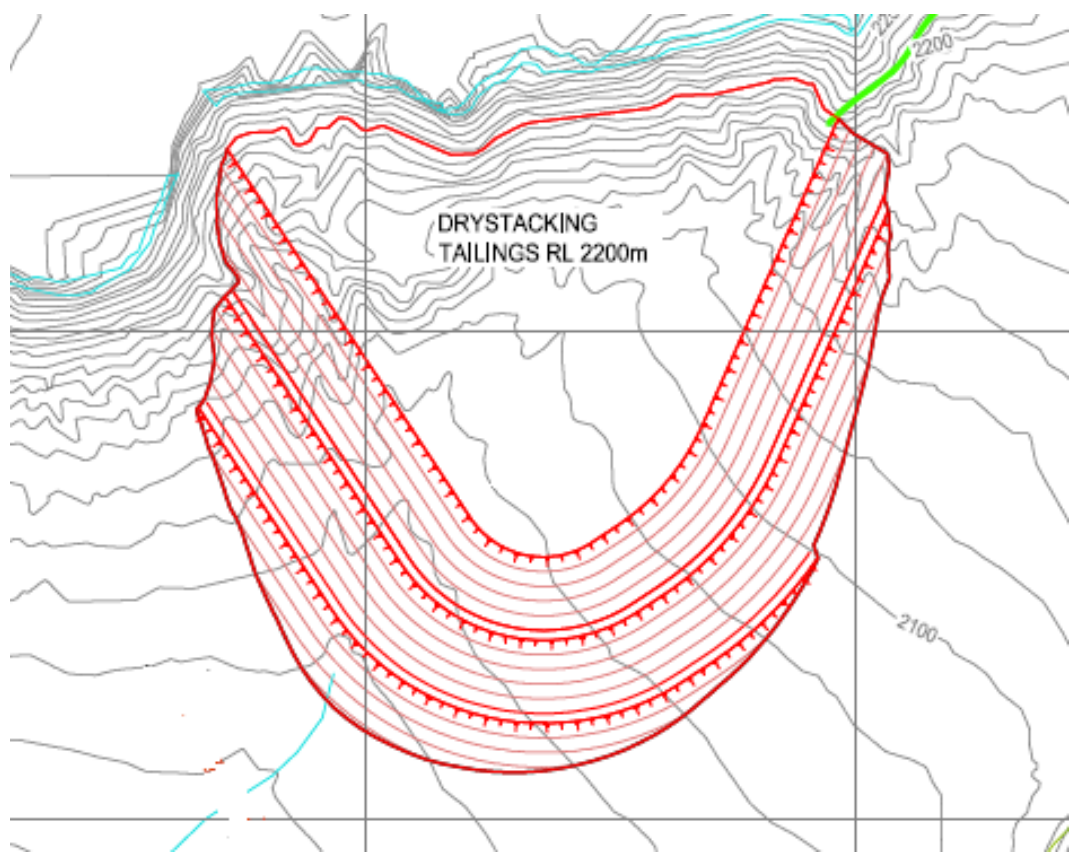

Figure 2 The dry stack TSF that was modelled for Mine 1 
Four options were considered for the tailings system for Mine 1:

a. High rate thicken the tailings slurry at the concentrator. Gravity pipeline the HR underflow to a site next to the TSF. Paste thicken the slurry there, and then pump it to the head of beach (HOB) to create the cone shaped tailings deposit as shown in Figure 2.

b. Paste thicken the tailings at the concentrator. Unlike the previous two options, this paste will be too viscous to flow to the TSF site by gravity, and will need to be pumped.

c. Gravity pipeline the unthickened tailings to a site next to the TSF. Paste thicken the slurry there, and then pump it to the head of beach (HOB) to create the cone shaped tailings deposit as shown in Figure 2.

d. High rate thicken the tailings slurry at the concentrator. Gravity pipeline the HR underflow to a site next to the TSF. Filter press the tailings there and distribute cake with conveyors.

In all four cases water return infrastructure is required. In the case of Option B, the pumps and pipeline are carrying much less water back to the concentrator. In the case of Option C, and especially so for Option D, the pumps and pipeline are carrying much more water back to the concentrator.

The civil, mechanical and electrical infrastructure required for each of these four options was designed and costed, including water costs. The results of the cost estimation are summarised in Table 3.

\section{Table 3 Cost estimate summary for mine 2 options study (figures are presented in M\$US)}

\begin{tabular}{cccccc}
\hline Option & $\begin{array}{c}\text { Total Capex } \\
\text { (capital expense) }\end{array}$ & $\begin{array}{c}\text { Upfront } \\
\text { Capex }\end{array}$ & $\begin{array}{c}\text { Annual Opex } \\
\text { (operating expense) }\end{array}$ & $\begin{array}{c}\text { NPC } \\
\text { (net present cost) }\end{array}$ & $\begin{array}{c}\text { NPC } \\
\text { (incl. water) }\end{array}$ \\
\hline A & 166 & 111 & 4.31 & 169 & 303 \\
B & 160 & 105 & 5.61 & 175 & 310 \\
C & 202 & 147 & 10.92 & 283 & 418 \\
D & 172 & 140 & 11.16 & 264 & 289 \\
\hline
\end{tabular}

From Table 3 it can be seen that Option D resulted in the lowest Net Present Cost when the water costs were included. Upon discussion with the mine owner, Option $D$ was chosen, not only for this reason, but also for the political impact in the local region, where water is highly valued.

\section{$5.2 \quad$ Mine 2}

This copper mine is located in a gently undulating area in a moderately dry climate. The tailings production rate will be 25 million tonnes per year (Mtpa) for a mine life of 26 years. The mine owner has stipulated that water and electricity consumption should be minimised.

Though the TSF site had already been decided, the type of dewatering technology had not. Therefore, in this options study a number of dewatering technologies were evaluated:

- High rate thickening.

- Paste thickening.

- Filtration.

It is expected that the discharge of high rate thickened tailings at a high flow rate will result in very low slopes on the tailings beach. Therefore, for the high rate option a conventional impoundment with large embankments was designed, which is presented in Figure 3. For the paste option a linear advancing centrally thickened discharge type tailings storage facility was designed. This TSF is presented in Figure 4. For the filtration option a large flat circular dry stack was proposed, with conveyors transporting the tailings 
filter cake to the centre of the stack, and earthmoving equipment proposed for distribution of the cake around the site.

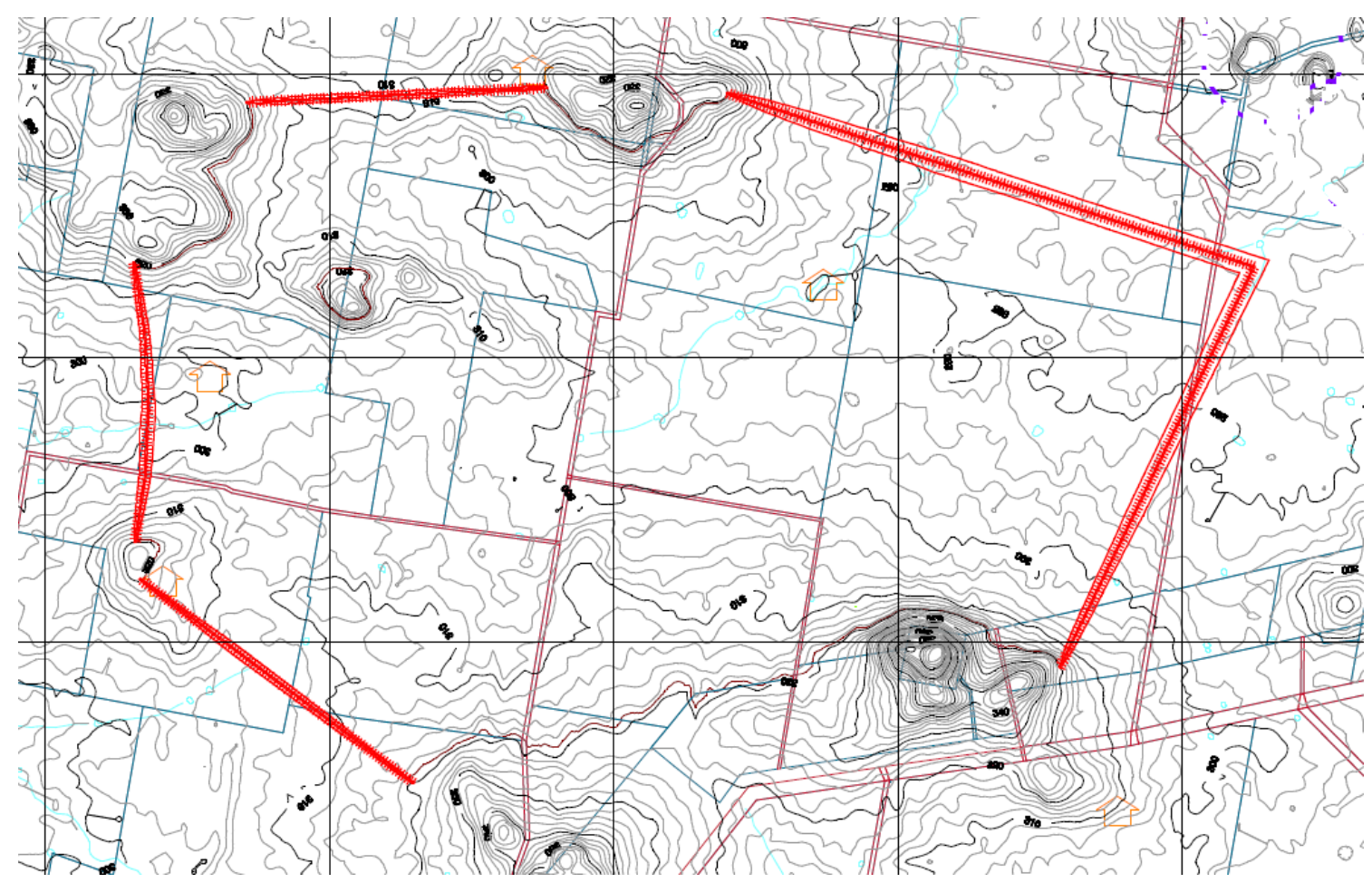

Figure 3 The impoundment TSF that was modelled for Mine 2

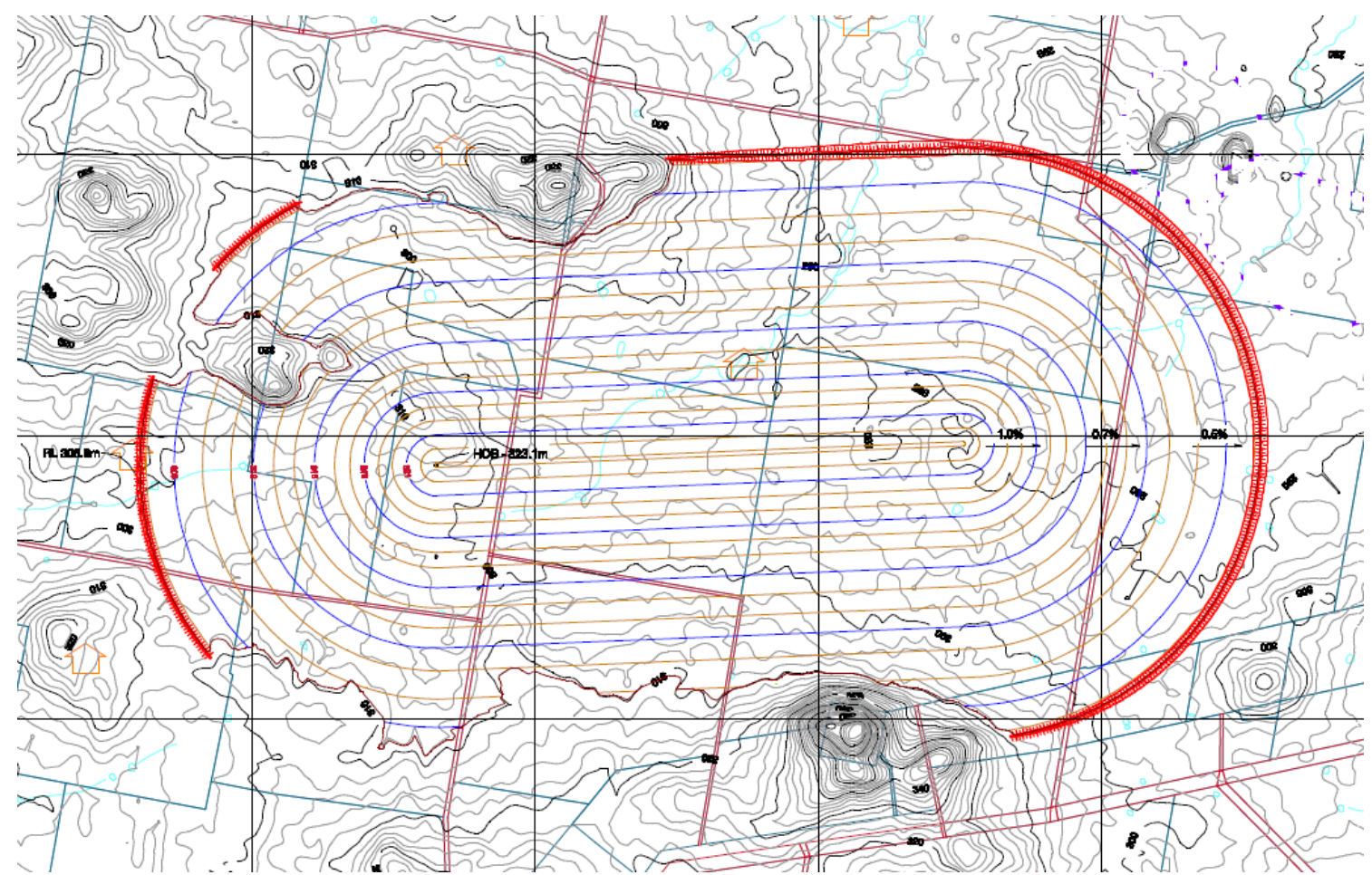

Figure 4 The linear advancing centrally thickened discharge TSF for Mine 2 
Five options were proposed for the tailings handling and transport system for Mine 2:

1. High rate thickeners at concentrator. Pump to TSF.

2. Paste thickeners at concentrator. Pump to TSF.

3. Pump unthickened tailings to TSF. Paste thickeners at TSF. Pump to HOB.

4. High rate thickeners at concentrator. Pump to TSF. Paste thickeners at TSF. Pump to HOB.

5. Filter tailings at concentrator. Transport filter cake to the TSF on a conveyor. Distribute cake with earthmoving equipment.

In all five cases water return infrastructure is required. In the case of Option $E$, there are pumps conveying the filtrate back to the concentrator, but minimal recovery of rainwater from the TSF.

The whole system (including embankments, mechanical and electrical infrastructure) required for each of these five options was designed and costed. The results of the cost estimation are summarised in Table 4.

Table 4 Cost estimate summary for Mine 2 options study (figures are presented in M\$US)

\begin{tabular}{ccccc}
\hline Option & $\begin{array}{c}\text { Total } \\
\text { Capex }\end{array}$ & $\begin{array}{c}\text { Upfront } \\
\text { Capex }\end{array}$ & $\begin{array}{c}\text { Annual } \\
\text { Opex }\end{array}$ & NPC \\
\hline A & 294 & 113 & 3.64 & 375 \\
B & 230 & 138 & 6.49 & 345 \\
C & 232 & 140 & 6.64 & 347 \\
D & 241 & 149 & 7.77 & 356 \\
E & 249 & 232 & 67.2 & 1074 \\
\hline
\end{tabular}

From Table 4 it can be seen that Option B resulted in the lowest Net Present Cost. Option B was recommended in this study for the following reasons:

- Lowest upfront capital expense.

- Lowest net present cost.

\subsection{Mine 3}

This copper mine is located in a mountainous area in an extremely dry climate. The tailings production rate will be 32 million tonnes per year (Mtpa) for a mine life of 30 years. The mine owner has stipulated that water recovery is to be maximised.

In this options study a TSF site had already been decided, but there was also a dry stack site that had been nominated for alternative dewatering options. In this options study the following dewatering technologies were evaluated:

- High density thickening of the entire tailings stream.

- Paste thickening of the entire tailings stream.

- Filter pressing of the entire tailings stream.

- Cyclone splitting with vacuum filtration of underflow and thickening of overflow. 
This selection of dewatering technologies resulted in the following three tailings storage scenarios being required:

- Storage of the entire thickened tailings stream in the TSF site.

- Storage of the entire filter pressed tailings stream in the dry stack site.

- Storage of the thickened cyclone overflow at the TSF site and the vacuum filtered cyclone underflow at the dry stack site (i.e. two storage sites).

The nominated TSF site is situated in a wide alluvial plain at the foot of the mountains. Due to the steep terrain in the area surrounding the mine, there were no efficient dam sites for the down valley storage of tailings slurry (i.e. all of the potential sites required massive embankments). For this reason, the nominated TSF site is situated $24 \mathrm{~km}$ from the mine, some 1,300 m lower. A drawing of the TSF site is presented as Figure 5, with a central thickened discharge storage shown.

The dry stack site was situated only $6 \mathrm{~km}$ from the concentrator, since the filter cake (and filtered sand) can be placed in sloping terrain with only small embankments required at the downstream toe of the dry stack to prevent silts from being carried downstream. The dry stack site is $50 \mathrm{~m}$ lower than the concentrator site. A drawing of the dry stack site is presented as Figure 6. A conveyor system is proposed for the initial distribution of the filter cake. Dozers are then required to push the cake away from the conveyors and groom the deposit.

Five options were proposed for the tailings handling and transport system for Mine 3:

1. High rate thickeners at concentrator. Gravity flow to TSF in an open channel flume. Paste thickeners at TSF. Pump to head of beach (HOB).

2. High rate thickeners at concentrator. Gravity flow to TSF in an open channel flume. High density thickeners at TSF. Pump to HOB.

3. High rate thickeners at concentrator. Gravity flow to dry stack site in a pipeline. Separate the slurry into sand and fines using cyclones. Dewater the sand using vacuum disc filters. Deposit sand into the dry stack site. Gravity flow the fines slurry via an open channel flume to Paste thickeners at TSF. Pump to HOB.

4. High rate thickeners at concentrator. Gravity flow to dry stack site in a pipeline. Separate the slurry into sand and fines using cyclones. Dewater the sand using vacuum disc filters. Deposit sand into dry stack site. Gravity flow the fines slurry via an open channel flume to high density thickeners at TSF. Pump to HOB.

5. High rate thickeners at concentrator. Gravity flow to dry stack site in a pipeline. Dewater the tailings using filter presses. Deposit filter cake into dry stack site using conveyors and dozers. 


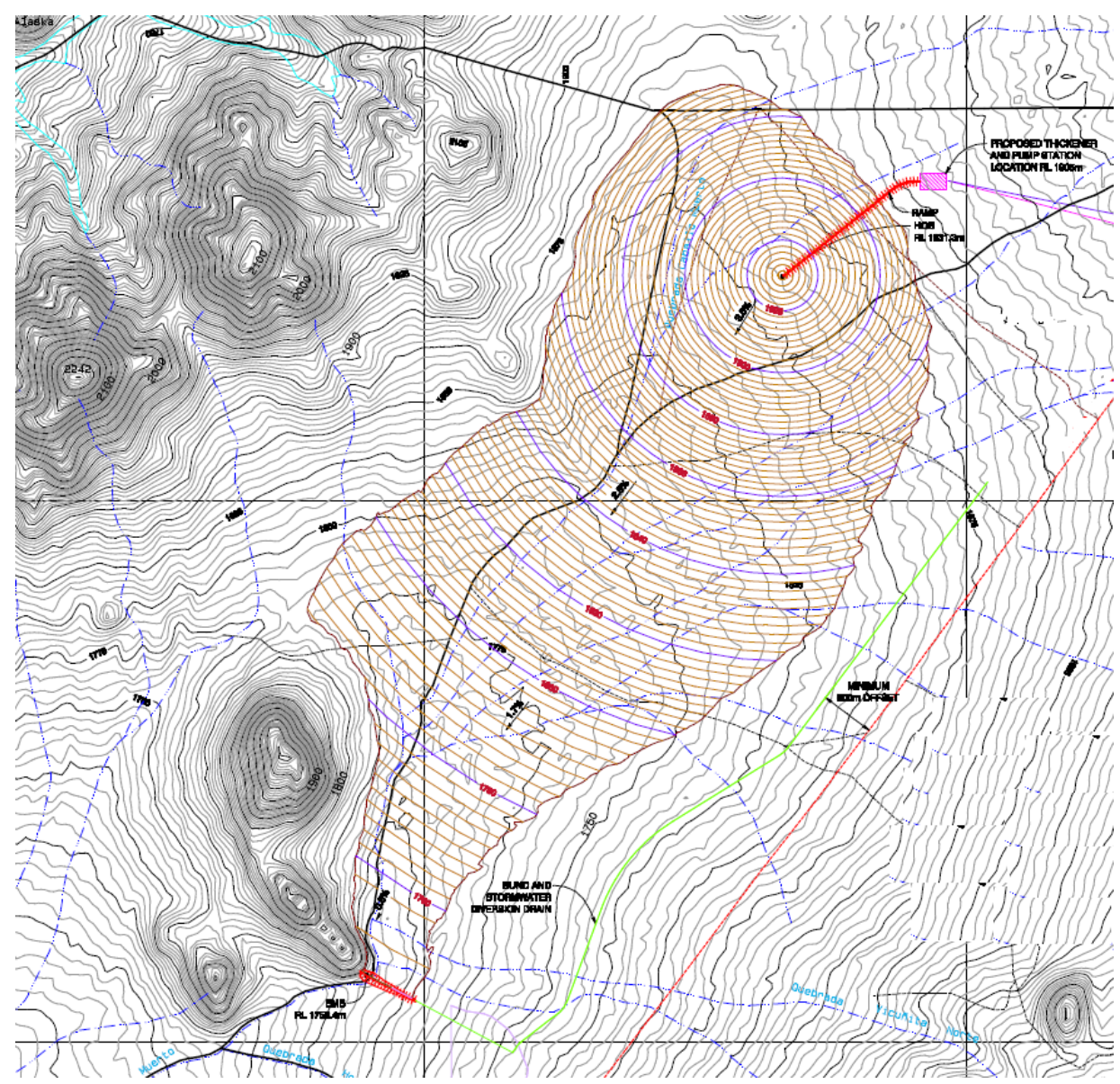

Figure 5 The central thickened discharge TSF that was modelled for Mine 3

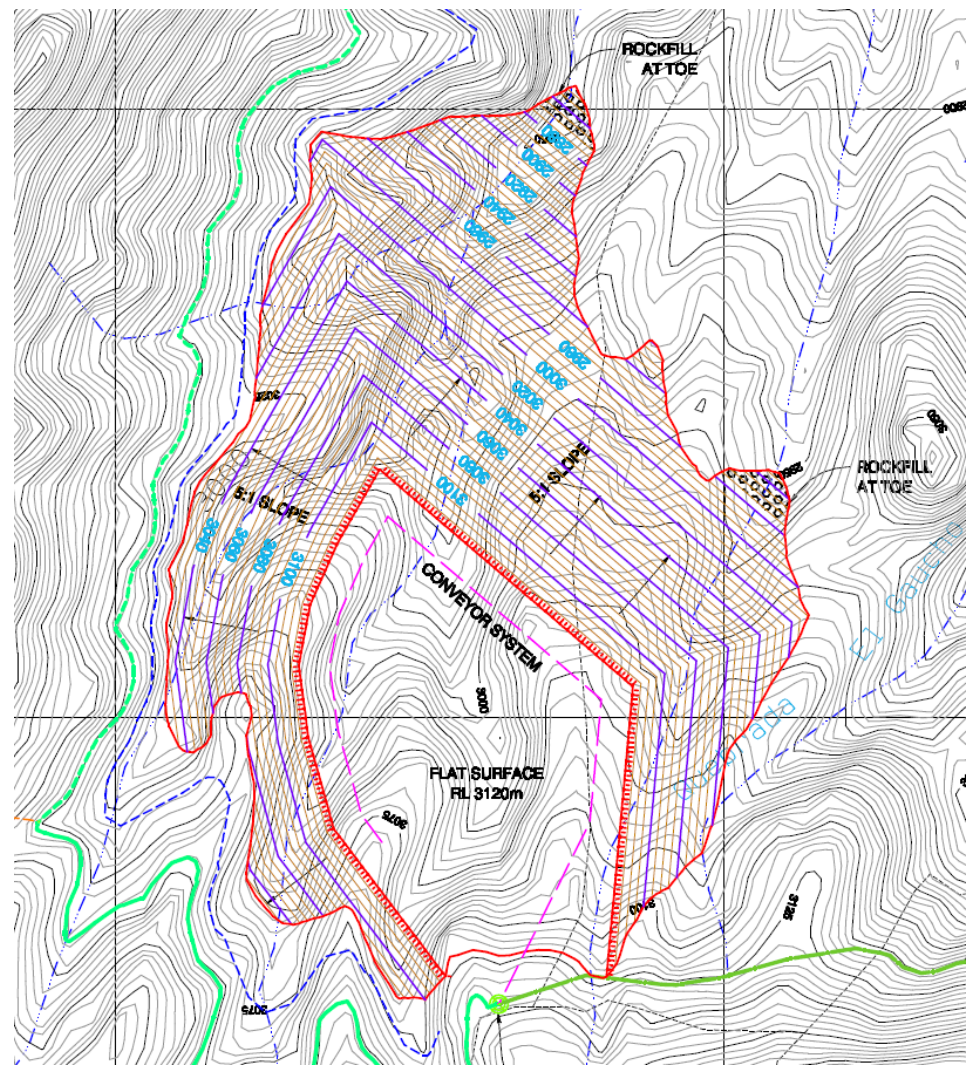

Figure 6 The dry stack that was modelled for Mine 3 
The whole system (including embankments, mechanical and electrical infrastructure, and closure) required for each of these five options was designed and costed. The results of the cost estimation are summarised in Table 5.

\section{Table 5 Cost estimate summary for mine 3 options study (figures are presented in M\$US)}

\begin{tabular}{ccccc}
\hline Option & $\begin{array}{c}\text { Total } \\
\text { Capex }\end{array}$ & $\begin{array}{c}\text { Upfront } \\
\text { Capex }\end{array}$ & $\begin{array}{c}\text { Annual } \\
\text { Opex }\end{array}$ & NPC \\
\hline A & 205 & 201 & 15.2 & 394 \\
B & 170 & 166 & 11.7 & 315 \\
C & 298 & 296 & 24.1 & 597 \\
D & 280 & 278 & 22.1 & 554 \\
E & 234 & 234 & 32.0 & 631 \\
\hline
\end{tabular}

From Table 5 it can be seen that Option B resulted in the lowest net present cost. Option B was recommended in this study for the following reasons:

- Lowest upfront capital expense.

- Lowest net present cost.

- Lowest operating costs.

It is noted that this option did not recover the greatest amount of water, but the cost of water was not high enough to justify the other options.

\section{$5.4 \quad$ Mine 4}

The final copper mine in our study is also located in a mountainous area in an extremely dry climate. The tailings production rate will be 47 million tonnes per year (Mtpa) for a mine life of 29 years. The mine owner has stipulated that water recovery is to be maximised, and has further set an upper limit for water consumption of 450 litres for every tonne of tailings stored.

In this options study a TSF site had already been decided, but there was also a dry stack site that had been nominated for filtration. In this options study the following dewatering technologies were evaluated:

- High density thickening of the entire tailings stream.

- Paste thickening of the entire tailings stream.

- Filter pressing of the entire tailings stream.

- Cyclone splitting with vacuum filtration of underflow and thickening of overflow.

This selection of dewatering technologies resulted in the following three tailings storage scenarios being required:

- Storage of the entire thickened tailings stream in the TSF site.

- Storage of the entire filter pressed tailings stream in the dry stack site.

- Storage of the thickened cyclone overflow at the TSF site and the vacuum filtered cyclone underflow at the dry stack site (i.e. two storage sites).

The nominated TSF site is situated in a wide alluvial plain at the foot of the mountains. Due to the steep terrain in the area surrounding the mine, there were no efficient dam sites for the down valley storage of 
tailings slurry (i.e. all of the potential sites required massive embankments). For this reason, the nominated TSF site is situated $25 \mathrm{~km}$ from the mine, some 1,600 m lower. A drawing of the TSF site is presented as Figure 7, with a Down Valley Discharge (DVD) scheme, though it more closely resembles a Central Thickened Discharge (CTD) scheme because the beach runs away from the discharge point in almost all directions (the difference between the two scheme types is the need for a ramp to be constructed that elevates the discharge point above the tailings). In order to alleviate the need for a ramp to provide access to the discharge point, it will be necessary to construct two saddle dams to the south east of this hill in order to prevent it being completely surrounded by tailings. It is noted that these saddle dams are not required for the cyclone split option, where this same site is used to store a smaller volume of tailings.

A relatively low embankment is required along the western edge of this TSF. For costing purposes, it has been assumed that the entire embankment is built at the beginning of the project. However, if a more detailed investigation of this option were pursued, the cost could be reduced with staged construction.

The dry stack site was situated only $6 \mathrm{~km}$ from the concentrator, at a site that is $50 \mathrm{~m}$ lower than the concentrator site. A drawing of the dry stack site is presented as Figure 8. A conveyor system is proposed for the major distribution of the filter cake, but it is noted that dozers are required to push the cake away from the conveyors and groom the sides of the deposit.

Five options were proposed for the tailings handling and transport system for Mine 4:

1. High rate thickeners at concentrator. Gravity flow to a site near the TSF in an open channel flume. Pump the slurry up to the high density thickeners, which are situated on a hill above the TSF. Gravity flow the thickener underflow down the hill to the TSF.

2. High rate thickeners at concentrator. Gravity flow to a site near the TSF in an open channel flume. Pump the slurry up to the Paste thickeners, which are situated on a hill above the TSF. Gravity flow the thickener underflow down the hill to the TSF.

3. Separate the slurry into sand and fines using cyclones. Dewater the sand using filter presses. Deposit sand into the dry stack site, using conveyors and dozers to distribute it. Gravity flow the fines slurry via an open channel flume to a site near the TSF. Pump the slurry up to the high density thickeners, which are situated on a hill above the TSF. Gravity flow the thickener underflow down the hill to the TSF.

4. Separate the slurry into sand and fines using cyclones. Dewater the sand using filter presses. Deposit sand into the dry stack site, using conveyors and dozers to distribute it. Gravity flow the fines slurry via an open channel flume to a site near the TSF. Pump the slurry up to the paste thickeners, which are situated on a hill above the TSF. Gravity flow the thickener underflow down the hill to the TSF.

5. High density thickeners at concentrator, then pressure filters. Convey cake to filter stack, and distribute using conveyors and dozers. 


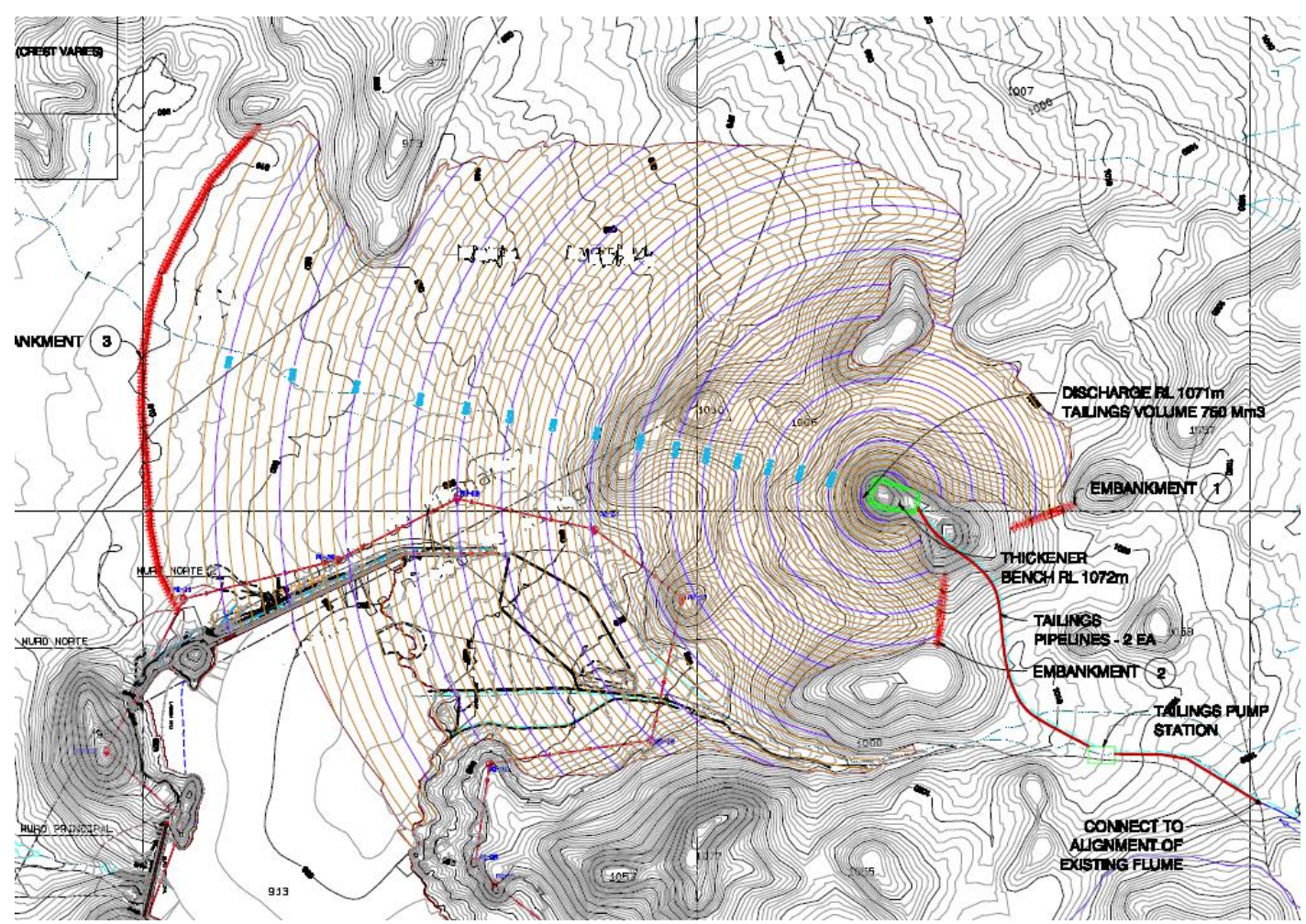

Figure 7 The down valley discharge TSF that was modelled for Mine 4

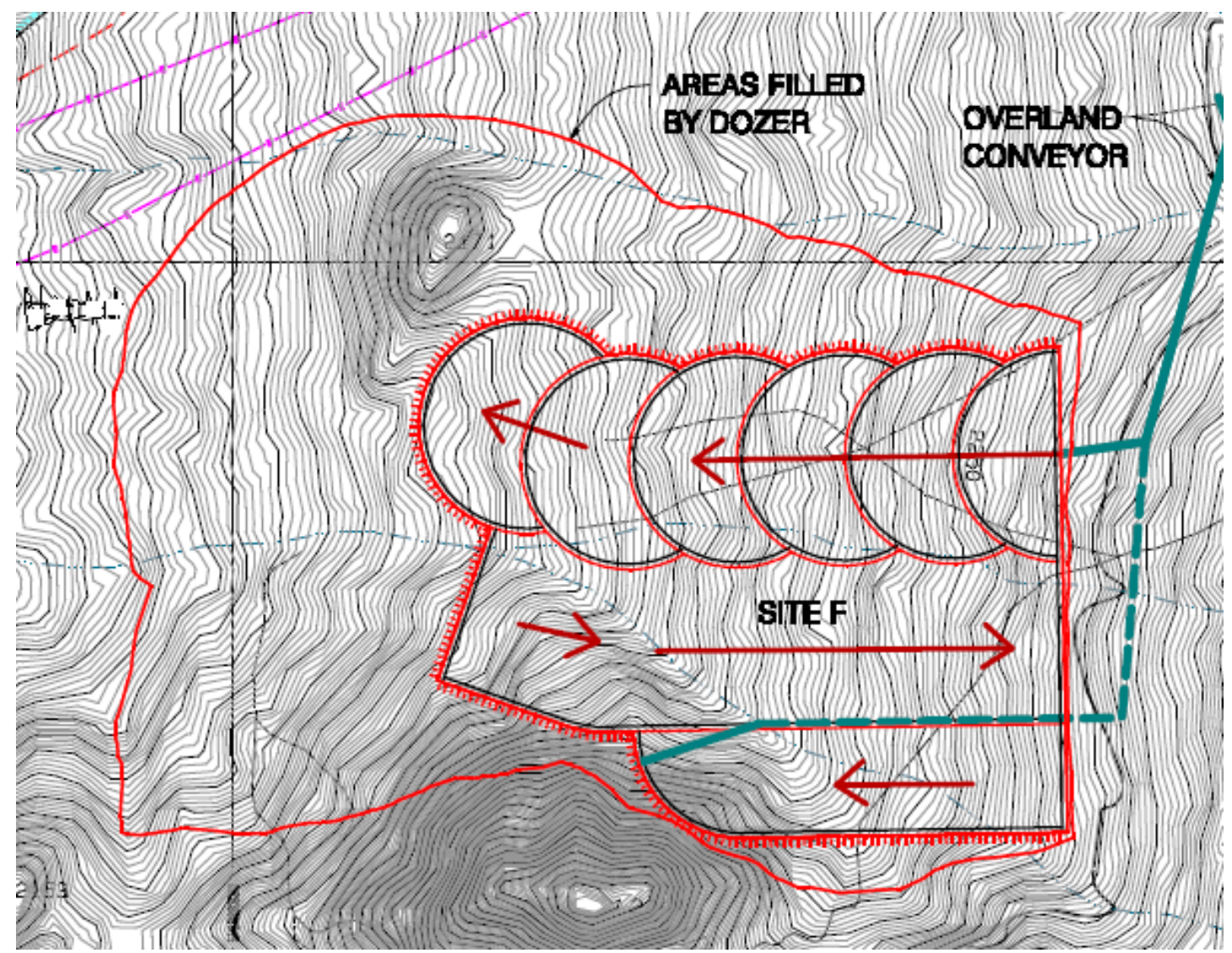

Figure 8 The dry stack that was modelled for Mine 4 
The whole system (including embankments, mechanical and electrical infrastructure and closure) required for each of these five options was designed and costed. The results of the cost estimation are summarised in Table 6.

\section{Table 6 Cost estimate summary for mine 4 options study (figures are presented in M\$US)}

\begin{tabular}{cccccc}
\hline Option & $\begin{array}{c}\text { Water } \\
\text { cons. } \\
\text { (I/t) }\end{array}$ & \multicolumn{4}{c}{ Findings of cost analysis } \\
\cline { 3 - 6 } & 538 & 213 & 213 & 16.9 & 421 \\
Capex & $\begin{array}{c}\text { Upfront } \\
\text { Capex }\end{array}$ & $\begin{array}{c}\text { Annual } \\
\text { Opex }\end{array}$ & NPC \\
\hline A & 538 & 275 & 275 & 19.2 & 510 \\
B & 471 & 275 & \\
C & 408 & 358 & 358 & 23.3 & 643 \\
D & 381 & 389 & 389 & 24.8 & 694 \\
E & 176 & 287 & 287 & 23.7 & 578 \\
\hline
\end{tabular}

From Table 6 it can be seen that Option A yielded the lowest costs in all three aspects considered. However, the water consumption figures for each option show that Options A and B both exceeded the client's specified $450 \mathrm{l} / \mathrm{t}$ limit (highlighted). Option $\mathrm{E}$ turned out to be the lowest cost option of the remaining three, but its NPV was \$157M USD dearer than Option A. We recommended that the mining company investigate the cost of water, since it may still be cheaper to produce slurry rather than dry stacking.

If the $450 \mathrm{l} / \mathrm{t}$ limit were upheld (for political reasons, for example), then Option $\mathrm{E}$ (filtration) would be our recommendation, since it is the cheapest of the three options operating below the $450 \mathrm{l} / \mathrm{t}$ limit.

\section{$6 \quad$ Water cost analysis}

In each of the projects studied here, the filtration option will be the cheapest if the cost of water is high enough. The minimum cost for water in order for the filtration option to break even with the cheapest alternative has been calculated for each of the four projects studied here. The findings of this analysis are summarised in Table 7.

Table 7 Break-even cost for water for each project

\begin{tabular}{cc}
\hline Mine & Break-even cost for water $\left(\mathrm{USD} / \mathrm{m}^{3}\right)$ \\
\hline 1 & 3.16 \\
2 & 8.40 \\
3 & 2.23 \\
4 & 0.76 \\
\hline
\end{tabular}

\section{Discussion}

Options studies such as those described in this paper are commonly carried out to enable the evaluation of various tailings handling and storage methods for a given project. Whilst the cost of water has a major impact on the dewatering technology that should be used, climate and topography also have a significant 
impact on tailings handling and storage, so there is by no means a simple 'one size fits all' approach that can be used. Each case must be considered on its own merits.

This work has shown that filtration technology is currently more expensive than slurry technology, but it has also shown how the cost of water can tip the balance in favour of filtration. The break-even figures presented in Section 5 show that filtration can become cost competitive with slurry technology in unfavourable topographic circumstances. Mine 4 provides a strong example of this: The slurry storage (and thickeners) are $25 \mathrm{~km}$ away from the concentrator, and 1,600 $\mathrm{m}$ lower. The filter storage is $6 \mathrm{~km}$ away and only $50 \mathrm{~m}$ lower. The cost of returning the overflow from the thickeners is huge, whilst the cost of returning the filtrate is modest, despite the volumetric flow rate being greater. Mine 2, in contrast, shows quite the opposite. The topography surrounding this mine is gently undulating, so both the slurry and cake TSFs are able to be located the same distance from the concentrator. In this case, the dry stacking option is vastly dearer than slurry, at about three times the cost. This highlights one of the less obvious (but significant) advantages of dry stacking compared to slurry storage, i.e. site selection is far more forgiving compared to slurry, particularly in mountainous terrain, where a site close to the concentrator may be viable for dry stacking but not for slurry storage. The dry stack can be shaped with steeper side slopes that are geotechnically stable, whilst slurry containments, with their relatively flat beaches and expensive dams, are very cost-sensitive to topography.

\section{Conclusions}

This paper concludes with the following key findings: The entire tailings system (including the tailings storage and the water return infrastructure) needs to be designed and costed in order to determine the most economic transport method for a given tailings storage scenario. The outcome can vary from one case to the next. There is no 'one size fits all'. Filtration was found to be considerably more expensive than the various thickening technologies studied. However, with a sufficiently high water cost, filtration can be cheaper than thickening. Generally, the more mountainous the terrain, the more viable it becomes to consider filtration instead of slurry.

\section{Acknowledgements}

The authors wish to acknowledge Ray Rieschieck for producing the mechanical designs and layouts in all four of the options studies presented here, Allan Thomas for carrying out the slurry pipeline design and analysis for the studies, and Keith Seddon for technical input and advice. 